\title{
Weekly predictions of North Atlantic right whale Eubalaena glacialis habitat reveal influence of prey abundance and seasonality of habitat preferences
}

\author{
Daniel E. Pendleton ${ }^{1,9, *}$, Patrick J. Sullivan ${ }^{1}$, Moira W. Brown ${ }^{2,9}$, \\ Timothy V. N. Cole ${ }^{3}$, Caroline P. Good ${ }^{4}$, Charles A. Mayo ${ }^{2}$, Bruce C. Monger ${ }^{5}$, \\ Steven Phillips ${ }^{6}$, Nicholas R. Record ${ }^{7,8}$, Andrew J. Pershing ${ }^{7,8}$ \\ ${ }^{1}$ Department of Natural Resources, Cornell University, Ithaca, New York 14853, USA \\ ${ }^{2}$ Provincetown Center for Coastal Studies, 5 Holway St., Provincetown, Massachusetts 02657, USA \\ ${ }^{3}$ National Marine Fisheries Service, Northeast Fisheries Science Center, Woods Hole, Massachusetts 02543, USA \\ ${ }^{4}$ Duke University Marine Lab, Beaufort, North Carolina 28516, USA \\ ${ }^{5}$ Ocean Resources and Ecosystem Program, Snee Hall, Cornell University, Ithaca, New York 14853, USA \\ ${ }^{6}$ AT\&T Labs-Research, Florham Park, New Jersey 07932, USA \\ ${ }^{7}$ School of Marine Sciences, University of Maine, Orono, Maine 04469, USA \\ ${ }^{8}$ Gulf of Maine Research Institute, 350 Commercial St., Portland, Maine 04101, USA \\ ${ }^{9}$ Present address: New England Aquarium, Central Wharf, Boston, Massachusetts 02110, USA
}

\begin{abstract}
Primary sources of mortality and serious injury to endangered North Atlantic right whales Eubalaena glacialis are vessel strikes and entanglement in fishing gear. All management plans depend on knowing when and where right whales are likely to be present. We tested the feasibility of a system designed to predict potential right whale habitat on a weekly time scale. The system paired right whale occurrence records with a collection of data layers including: results from a coupled biological-physical model of Calanus finmarchicus (the primary prey of right whales), satellite-derived sea surface temperature and chlorophyll, and bathymetry. Using these data, we trained seasonal habitat models and projected them onto environmental data for each 8 d period from January to June, 2002 to 2006. Two hypotheses were tested: (1) that right whale environmental preferences change from season to season and (2) that modeled prey concentration is an important predictor of the distribution of right whales. To test $H_{1}$, we trained, tested, and compared models for 3 time periods: winter, spring, and winter and spring combined. To test $H_{2}$, we trained and tested models with and without $C$. finmarchicus. Predictions of habitat suitability were highly dynamic within and across years. Our results support the hypothesis that right whale environmental preferences change between winter and spring. The inclusion of modeled C. finmarchicus abundance improved the accuracy of habitat suitability predictions.
\end{abstract}

KEY WORDS: Right whale $\cdot$ Eubalaena glacialis $\cdot$ Calanus finmarchicus $\cdot$ Species distribution model $\cdot$ Gulf of Maine $\cdot$ Transferability

Resale or republication not permitted without written consent of the publisher

\section{INTRODUCTION}

North Atlantic right whales Eubalaena glacialis are endangered. Despite protective measures, vessel collisions with whales and entanglement in fishing gear continue to pose significant risk to these animals
(Knowlton \& Kraus 2001, Kraus et al. 2005). This high level of threat is due, in part, to overlap of right whale habitat with commercially important shipping and fishing areas. Thus, there is an economic incentive to resist measures, especially blanket restrictions, designed to protect right whales from human en- 
counters. There is an ongoing effort to find solutions that will help to reduce risk to right whales without placing undue restrictions on shipping and fishing activities (Myers et al. 2007). Temporally and spatially dynamic protective measures could ease some of the tension between commercial and conservation interests.

We know where to find right whales within large spatial and temporal windows (Winn et al. 1986). During winter, females can be found giving birth in the coastal waters of the southeast USA (Kraus et al. 2007). From winter to mid-spring, a portion of the population can be found in Cape Cod Bay (Fig. 1) off the northeast US coast (Mayo et al. 2004). Beginning in mid-spring and extending into the summer, right whales can be found in the Great South Channel (CETAP 1982, Kenney \& Wishner 1995). In the late summer and fall, right whales can be found in the Bay of Fundy and Roseway Basin (Brown et al. 2009). With few exceptions (e.g. Kenney 2001, Patrician \& Kenney 2010), these patterns are predictable on seasonal timescales and at regional spatial scales. Protective measures such Seasonal Area Management zones (NOAA 2002), the mandatory ship reporting system (Ward-Geiger et al. 2005), vessel speed restrictions (NOAA 2008), and the boundaries of the USA (NOAA 1994) and Canadian (Brown et al. 2009) Critical Habitats have been based upon these known distributional patterns.

A leading hypothesis to explain the distribution of right whales in the Gulf of Maine is that whales move to areas with high concentrations of prey, relative to nearby regions. The aggregation of right whales in regions rich in late-stage Calanus finmarchicus (hereafter Calanus) has been well documented (Wishner et al. 1988, 1995, Murison \& Gaskin 1989, Baumgartner et al. 2003a). Sighting records indicate that individual right whales utilize both Cape Cod Bay and the Great South Channel in the same year (NARWC 2011a, P. Hamilton pers. comm.). Pendleton et al. (2009) examined abundance of right whales with respect to 2 groups of prey: (1) Calanus and (2) Pseudocalanus spp. and Centropages typicus. The authors found that regional-scale mean concentration of prey is a statistically significant predictor of the relative abundance of right whales. Right whales in Cape Cod Bay appeared to respond more strongly to the concentration of Pseudocalanus spp. and $C$. typicus than to Calanus. However, in the Great South Channel, right whale abundance was more strongly correlated with Calanus than with other prey taxa. This suggests that (1) the environmental preferences of right whales are dynamic and change on seasonal time scales, and (2) the distribution and availability of prey are important factors in determining the distribution of right whales.

Pershing et al. (2009a) went on to build and ground-truth a model of Calanus abundance throughout the Gulf of Maine, and Pershing et al. (2009b) found a statistically significant relationship between modeled concentration of Calanus and the arrival date of right whales in the Great South Channel region. Thus, modeled concentration of Calanus was found to be a good predictor of right whale abundance at regional spatial scales. Finerresolution estimates of where and when right whales are likely to occur, within and between years, are needed so that government managers can issue alerts to mariners regarding the likelihood of right whale occurrence.

For this study, we modeled the distribution of right whale habitat on small space $(1 \mathrm{~km})$ and short time (weekly) scales. Our objective was to build a model that could identify potential right whale habitat on a weekly time

Fig. 1. Gulf of Maine region, with Cape Cod Bay at lower left and Nova Scotia at upper right. Bold rectangle is the region for which habitat suitability was estimated. Bathymetry is depicted by shading. From light to dark, shades represent land, 0-80, $80-200,200-1000$ and $>1000 \mathrm{~m}$. Gulf of Maine right whale Critical Habitats are identified by polygons: Cape Cod Bay (CCB), Great South Channel (GSC), Bay of Fundy (BoF), and Roseway Basin (RB) 
scale, and that was sensitive to intra- and interannual variability in environmental conditions. Within that purview, we tested 2 hypotheses: $H_{1}$ : that right whale environmental preferences differ between seasons, and $H_{2}$ : that prey is an important predictor of the spatial and temporal distribution of right whales.

\section{MATERIALS AND METHODS}

\section{Study region and species occurrence records}

Habitat suitability was modeled in 2 important right whale Critical Habitats: Cape Cod Bay and the Great South Channel (Fig. 1). Right whale occurrence records were collected during right whale aerial surveys conducted by the Provincetown Center for Coastal Studies (Mayo et al. 2004) and the US National Marine Fisheries Service (Cole et al. 2007), and were obtained from the North Atlantic Right Whale Consortium database. Our study used occurrence records for the years 2002 to 2006. Records from opportunistic and directed surveys to known aggregations of right whales were excluded from our analysis. Only records from randomized or complete trackline surveys were used (Brown et al. 2007, Cole et al. 2007). All occurrence records and environmental data came from the region spanning $40.5^{\circ}$ to $42.5^{\circ} \mathrm{N}$ latitude and $71.0^{\circ}$ to $67.0^{\circ} \mathrm{W}$ longitude. In response to the vertical distribution of the prey, right whales often go on extended (8 to $10 \mathrm{~min}$ ) feeding dives and spend a considerable amount of time underwater (Goodyear 1996). Visual surveys only detect whales at or near the surface; therefore, true absence cannot be inferred from visual absence. For this reason, right whale occurrences were treated as a presence-only dataset.

\section{Environmental data layers}

Three dynamic predictor variables and 1 static predictor variable were used to model right whale habitat suitability. Dynamic predictor variables change every $8 \mathrm{~d}$, while static variables do not change. Dynamic predictor variables included $8 \mathrm{~d}$ mean sea surface temperature (SST), chlorophyll, and modeled Calanus abundance. The static predictor variable was a TOPEX-derived bathymetric grid, linearly interpolated to $1 \mathrm{~km}$ resolution, indicating water depth (Smith \& Sandwell 1997).

SST measurements for the years 2002 and 2003 were obtained from the Advanced Very High Resolu- tion Radiometer and were available as Level 3 coverages $(4 \mathrm{~km}$ resolution) from the NOAA-NODC Pathfinder V5 Project. These data were downsampled to $1 \mathrm{~km}$ resolution to match the resolution of the majority of our satellite data. SST measurements for the years 2004 to 2006 came from the Moderate Resolution Imaging Spectrometer (MODIS) instrument on the Aqua satellite. Chlorophyll measurements were obtained from the Sea-viewing Wide Field-ofview Sensor (SeaWiFS) for the year 2002. In order to avoid periodic gaps coverage caused by SeaWiFS outages, chlorophyll data for 2003 to 2006 were obtained from the MODIS instrument on the Aqua satellite, which came online in mid-2002. SeaWiFS and MODIS-Aqua chlorophyll data sources are comparable (Zhang et al. 2006). SST and chlorophyll data from MODIS-Aqua and SeaWiFS were downloaded as Level 2 coverages $(1 \mathrm{~km}$ resolution) from the Ocean Color Web (http://oceancolor.gsfc.nasa.gov). Daily satellite imagery was processed into $8 \mathrm{~d}$ means using a simple arithmetic mean, and was then interpolated to eliminate pixels with missing data, which were a consequence of cloud cover. We used the interpolation procedure described by Pershing et al. (2009a). All chlorophyll data were $\log _{10}(x+1)$ transformed. Values of predictor variables at each pixel were georeferenced, and the collection of values for each environmental variable over the model domain is referred to as an environmental data layer.

The modeled Calanus abundance estimates used in our study were described in detail by Pershing et al. (2009a). Briefly, the model couples a Calanus lifehistory model to output from an ocean circulation model. For this study, we used climatological circulation fields from Naimie (1996). These fields contain realistic seasonal changes in circulation, but do not vary from year to year. The model was initialized with a climatological spatial Calanus distribution from January. The abundance of Calanus in January was adjusted in each year using data from the Gulf of Maine continuous plankton recorder survey (Jossi \& Goulet 1993). The dynamical evolution of the Calanus abundance field was then determined by satellite estimates of SST, which determines development rate (Campbell et al. 2001), and chlorophyll, which determines egg production (Runge \& Plourde 1996, Durbin et al. 2003). The model was run from 1 January through 31 May. After 1 June, many Calanus exhibit diel vertical migration, although this is highly variable (Durbin et al. 1995). Furthermore, many subadults (C5s) enter a state of reduced activity known as diapause, typically below $150 \mathrm{~m}$. Both the daily and seasonal vertical migrations make it diffi- 
cult for our model, which is forced mainly by surface data, to reproduce the dynamics of this population during the summer. Overall, the model does a good job capturing the seasonal development of the Calanus population in the Gulf of Maine and reproducing the interannual variability in right whale prey (Pershing et al. 2009a).

Although SST and chlorophyll data were used to force the Calanus model, all 3 products were used as predictors in our model and were treated as independent variables for the following reasons. Due to the long generation time of Calanus (30 to $100 \mathrm{~d}$, depending on temperature), there is a highly variable and nonlinear time lag between the environmental variables and the modeled Calanus distribution. Temperature and chlorophyll act differently on each life stage of Calanus. Therefore, modeled Calanus abundance is not linearly related to SST or chlorophyll. The relationship between SST and chlorophyll inputs and Calanus output is further complicated because the Calanus life-history model is embedded in a circulation model. Thus, the modeled Calanus abundance at a particular location is a non-linear integration of past SST and chlorophyll conditions from a range of upstream locations.

\section{Modeling algorithm}

We used the maximum entropy method, or Maxent, to model the relationship between right whale occurrence and environmental covariates. Entropy is a measure of uniformity. The goal of the Maxent algorithm, applied in the context of species distribution modeling, is to produce an estimate of the unknown distribution describing the relationship between the species occurrences and a set of measured environmental predictor variables (i.e. covariates). The estimated distribution should maximize entropy subject to a set of constraints representing what is known (Phillips et al. 2006), or minimize relative entropy (Elith et al. 2011). Here we provide a conceptual overview of the algorithm, following Elith et al. (2011), but refer readers to additional publications for detailed explanations (Phillips et al. 2004, 2006, Phillips \& Dudik 2008).

The core of the Maxent algorithm is an estimate of the ratio of the conditional density of the covariates at the occurrence locations to the unconditional density of covariates across the study area as measured by a random sample of the background. Maxent chooses the conditional density such that the distance between it and the unconditional density is mini- mized, subject to a set of constraints, e.g. that the mean temperature in the conditional density be close to the mean temperature across occurrence locations. The resultant Maxent model has an exponential form. Elith et al. (2011) provided a detailed yet accessible description of the Maxent algorithm. We implemented the algorithm using the Maximum Entropy Species Distribution Modeling Software v3.3.1g using default options and the logistic output. The logistic output format provides habitat suitability values that can be interpreted as the probability of species presence, conditioned on the environmental variables (Phillips \& Dudik 2008).

In many applications of Maxent there is 1 data layer for each environmental variable. In such cases, background data (Hirzel et al. 2002) consist of a random sample of points from the study area, with associated values of all the environmental variables. In our study there was 1 data layer for each environmental variable for each $8 \mathrm{~d}$ period. Therefore, background data for each model that we trained was taken from 10000 randomly chosen location-time pairs (latitude, longitude, and time measured in $8 \mathrm{~d}$ periods) from the model training dataset (Phillips \& Dudik 2008). The quantity 10000 has been experimentally determined to be a sufficient number of background samples to ensure that the area under the receiver operator characteristic (ROC) curve (AUC; see 'Model Evaluation' section below) no longer changes as the number of background samples is increased (Phillips \& Dudik 2008), and it is the default number used in Maxent software. Each background sample has the values of each environmental variable at that location and time, as do the right whale presence samples. Background data therefore represent a sample of conditions across space and time that the whales were choosing from. If no whales were sighted during a particular $8 \mathrm{~d}$ period, then environmental data from that period were excluded from the data available to be sampled to generate the background dataset.

\section{Experimental design}

Environmental and species occurrence data (spanning 1 January to 1 June for the years 2002 to 2006) was temporally partitioned into 5 subsets to facilitate a cross validation procedure in which $4 \mathrm{yr}$ of data were used to train a model and the fifth year (the test year) was used to test the model. For example, the model trained with data from the years 2003 to 2006 was projected onto environmental data from all $8 \mathrm{~d}$ 
periods in 2002, yielding 1 habitat suitability map for each 8 d period in 2002. Each right whale occurrence from 2002 was then associated with the prediction of habitat suitability for the time ( $8 \mathrm{~d}$ period) and location of the occurrence. Then, performance of the model in the test year was measured (see 'Model Evaluation' section below).

To address $H_{1}$, that right whale habitat preferences are dynamic, we conducted 3 experiments. In the first experiment, we trained and tested models with data from winter (1 January to $21 \mathrm{March}$ ), in the second experiment we used data from spring (22 March to 1 June), and in the third experiment we used data from winter-spring (1 January to 1 June). The yearly cross validation scheme was used for each of these experiments, yielding 5 models ( 1 for each test year) for each experiment. A difference in the relative influence of predictors in winter versus spring experiments would suggest that the habitat preference of right whales changes on a seasonal basis.

To address $H_{2}$, that prey is an important predictor of right whale habitat preferences, we compared the predictive accuracy of models trained with and without modeled Calanus for each season outlined above. This doubled the number of experiments (and therefore the number of models). A subscript $C$, e.g. winter-spring $_{C}$, was used to label experiments that included the modeled Calanus predictor variable. Statistical significance was determined by estimating confidence intervals using the delete-d jackknife procedure described below. Non-overlapping confidence intervals indicated a statistically significant difference.

\section{Model evaluation}

AUC is a standard performance metric for presence-only species distribution models, and for many other classifiers (Hanley \& McNeil 1982, Swets 1988, Fawcett 2006). Although AUC is sensitive to sample size and other aspects of model structure (Hernandez et al. 2006, Wisz et al. 2008), it is an important metric for measuring model performance. We calculated 1 AUC score for each seasonal model in each test year, for a total of 30 scores. The ROC curve is a plot of the true positive classification rate (sensitivity) versus the false positive classification rate (1-specificity). The total area of the plot is equal to 1 . A ROC curve that is a diagonal line from the lower left to the upper right corner is the theoretical ROC curve for a random model and produces an AUC $=0.5$. A higher AUC score indicates better predictive accuracy of the model. For example, an AUC of 0.8 indicates that there is an $80 \%$ chance that the predicted habitat suitability for a randomly drawn species presence will be higher than that of a randomly drawn absence (Fawcett 2006). In a presence-only model there are no species absences, so computing a false positive rate is not possible. Rather than distinguish presence from absence, we distinguished presence from random or background data, also known as pseudoabsence data (Ferrier et al. 2002, Phillips et al. 2006, Phillips \& Dudik 2008).

Commonly, a single model is applied to a single set of data layers, and a single AUC score is calculated. In our study, we applied a single seasonal model to many sets of environmental data layers, generating 10, 9, and 19 habitat suitability maps for experiments from the winter, spring, and winter-spring periods, respectively. To deal with this, we concatenated habitat suitability maps from all $8 \mathrm{~d}$ periods within each experiment and test year and calculated 1 AUC score. For example, we calculated 1 AUC score for winter 2002. To accomplish this, all habitat suitability maps for $8 \mathrm{~d}$ periods in test year 2002, during which right whales were observed, were layered to create 1 array. Time periods with no right whale sightings were ecluded to bring the bias of the background data into closer agreement with the bias of the aerial survey data (Phillips et al. 2009). From the layered array, 10000 coordinate locations, indexed by $i$, were chosen uniformly at random with replacement. The value of habitat suitability, $S(i) \in[0,1]$, at each of those locations was stored, and these $S(i)$ were the pseudo-absence background data. For a series of threshold values, $t \in[0,1], t=0,0.05,0.01, \ldots, 1$, 1 -specificity was calculated as the percentage of $S(i) \geq t$. The true positive classification rate (TPR or sensitivity) was calculated as the fraction of right whales occurring at locations where the habitat suitability value was $\geq t$. TPR was then plotted as a function of 1-specificity to generate the ROC curve. Intuitively, the quantity 1-specificity can be thought of as, and is nearly the same as (Phillips et al. 2006), the proportion of pixels predicted to be suitable given the threshold value $t$. The area under the ROC curve was then summed to calculate the AUC score.

We used the delete-d jackknife resampling procedure (Efron \& Tibshirani 1994) to generate $90 \%$ confidence intervals around each AUC score. The procedure was implemented in the following way: from the total of $n$ occurrence locations for each season / test year combination, a subset of size $n-d$, where $d=\sqrt{n}$ rounded up to the nearest integer, was drawn randomly and without replacement. This procedure was 
repeated 100 times for each season and test year. One hundred Maxent models were then fit, and 100 AUC scores were calculated. For consistency with original experiments, pseudo-absence background data were sampled in the manner described above. Confidence intervals were plotted by ranking the AUC scores and plotting the 5th through the 95th greatest values (Fig. 2). Confidence intervals for models fit with and without Calanus in each test year were compared to determine whether there was a statistically significant difference in AUC, with non-overlapping intervals indicating a significant difference.

To assess the capacity of seasonal models to generate consistent predictions regardless of test year, we calculated the variance in true positive rate (hereafter TPR variance). TPR variance is measured directly from the data in ROC plots, and it is the variance in TPR across the 5 ROC curves (1 for each year) for each experiment. TPR variance was measured at all threshold values, $t \in[0,1], t=0,0.05,0.01, \ldots, 1$, and was plotted as a function of 1-specificity. The advantage of calculating TPR variance versus variance in AUC scores is that TPR variance provides information on how predictions vary as the threshold for good habitat varies, and that information is lost when an AUC score is calculated. If the TPR variance for a set of models (i.e. spring) was low and the associated AUC scores were high, it means that models trained for that season made consistently good predictions in all years. If the TPR variance was low and the associated AUC scores were low, it means that the models trained for that season made consistently poor predictions. Thus, low TPR variance among models is associated with low interannual variability in predictive accuracy.

\section{RESULTS}

\section{AUC}

All AUC scores (Table 1) obtained were above 0.7 . Thirty percent were between 0.7 and $0.799,53.33 \%$ were between 0.8 and 0.899 , and $16.67 \%$ were between 0.9 and 1.0 (Table 1). Mean AUC for the winter period experiments was higher than for the winter-spring period experiments, and the score for the winter-spring period experiments was higher than for the spring period experiments. The mean AUC score for the winter-spring models using Calanus (winter-spring C $_{\text {) }}$ was higher than the models without Calanus (winter-spring). The mean AUC for the spring models with Calanus (spring ${ }_{C}$ ) was also higher than the models without Calanus (spring).

In all models trained with data from the winterspring period, except 2006, the inclusion of Calanus significantly improved AUC scores (Fig. 2a). Inclusion of Calanus made the AUC score for the year 2006 significantly worse. There was no significant effect of Calanus in predictions of models trained with data from the winter period (Fig. 2b). Three out of 5 models trained with data from the spring period were significantly improved by the inclusion of Calanus (Fig. 2c). As with the winter-spring period,

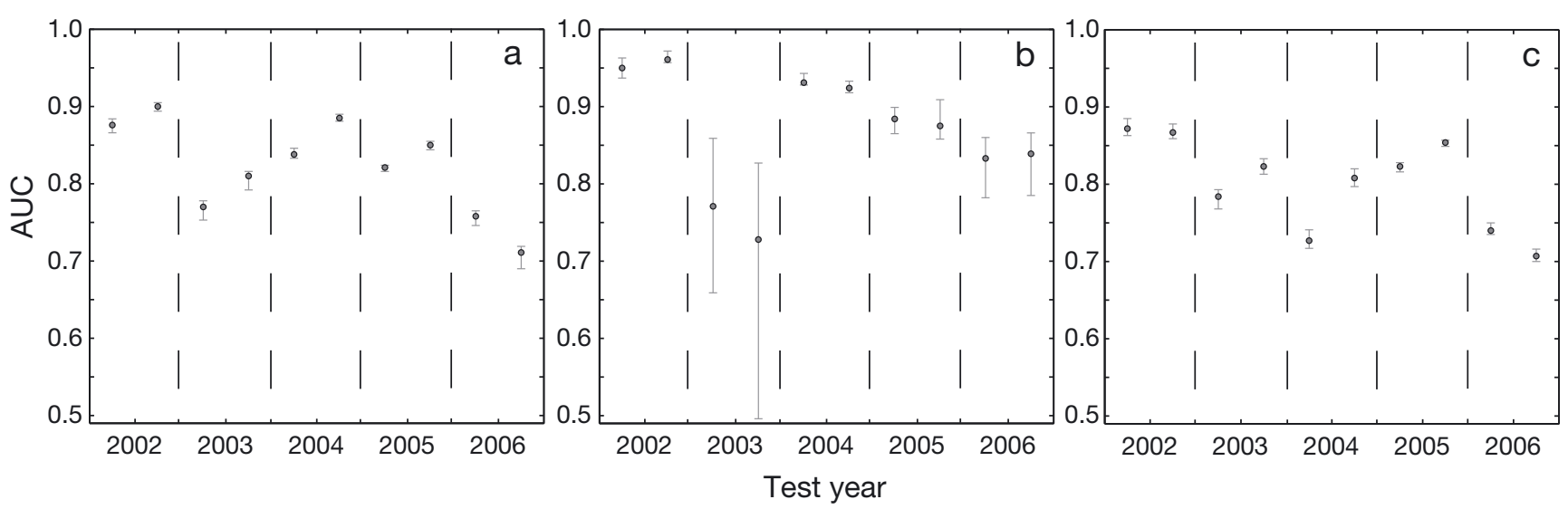

Fig. 2. Confidence intervals $(90 \%)$ on the area under the receiver operator characteristic (ROC) curve (AUC) scores for each model, generated with the delete-d jackknife resampling procedure. Models are (a) winter-spring and winter-spring ${ }_{\mathrm{C}}$ (b) winter and winter $_{\mathrm{C}}$ and (c) spring and spring ${ }_{\mathrm{C}}$. Subscript C indicates models in which Calanus was included as a predictor variable. Years are separated by dashed lines. Dots are original model AUC scores shown in Table 1. Data on the left side of each column (i.e. year) are for the model trained without Calanus, and data on the right side of columns show models where Calanus was included as a predictor variable. Non-overlapping confidence intervals in each test year indicate that there was a significant difference between models trained with versus without Calanus. Note that vertical axes show approximately half of the full range [0 1] for AUC 
Table 1. Area under the curve (AUC) scores, calculated from receiver operator characteristic (ROC) curves of habitat suitability maps in each test year for each experiment: winter-spring and winter-spring ( $_{C}$ ( January to 1 June), winter and winter ${ }_{C}$ and (1 January to $21 \mathrm{March}$ ), spring and spring ${ }_{C}(22$ March to 1 June). Subscript C indicates models in which Calanus was included as a predictor variable. Numbers in parentheses are the number of right whale occurrences used in model testing and training, respectively

\begin{tabular}{|lcccccc|}
\hline Test year & Winter-spring & Winter-spring & Winter & Winter $_{C}$ & Spring & Spring $_{C}$ \\
\hline 2002 & $0.876(133,856)$ & $0.900(133,856)$ & $0.950(18,188)$ & $0.961(18,188)$ & $0.872(115,668)$ & $0.867(115,688)$ \\
2003 & $0.770(143,846)$ & $0.810(143,846)$ & $0.771(7,199)$ & $0.728(7,199)$ & $0.784(136,647)$ & $0.823(136,647)$ \\
2004 & $0.838(227,762)$ & $0.885(227,762)$ & $0.931(120,86)$ & $0.924(120,86)$ & $0.727(107,676)$ & $0.808(107,676)$ \\
2005 & $0.821(271,718)$ & $0.850(271,718)$ & $0.884(43,163)$ & $0.875(43,163)$ & $0.823(228,555)$ & $0.854(228,555)$ \\
2006 & $0.758(215,774)$ & $0.711(215,774)$ & $0.833(18,188)$ & $0.839(18,188)$ & $0.740(197,586)$ & $0.707(197,586)$ \\
Mean AUC & 0.813 & 0.831 & 0.874 & 0.865 & 0.789 & 0.812 \\
\hline
\end{tabular}

the spring period model for test year 2006 was made significantly worse by adding Calanus. To alleviate concerns over the potential impact of sample size on AUC (Hernandez et al. 2006, Wisz et al. 2008), we performed a linear regression between AUC and the number of occurrence records used in training or testing of each model. No relationship was found.

One of the primary objectives of this study was to produce a model that could make good predictions of habitat suitability, not only within each year, but also from year to year. We were therefore interested in models for which AUC scores (Table 1), and shape of ROC curves, were similar from year to year. As was reported above, AUC scores for individual test years were generally good. The main exceptions were the scores for winter-spring ${ }_{C}$ and spring ${ }_{C}$ models for test year 2006 (Table 1), which were low in comparison with others.

Ideally, the modeled relationship between species and environment should provide accurate results even as environmental conditions change from year to year. We assessed the capacity of models to provide consistent performance across test years by plotting TPR variability (Fig. 3). Lower variability corresponds to more consistent model performance across test years. Variability in the winter period experiments was more than 5 times higher than for the winter-spring and spring period experiments. To aid examination of the low variance results, we removed the higher variance results (Fig. 3c,d). Removing the results for 2006 (Fig. 3a,c) allowed for comparison of TPR variance in winter-spring and spring period experiments with and without Calanus. The degree of consistency in model performance, from greatest to least after removing the results for 2006, is winter-spring ${ }_{C}$, spring ${ }_{C}$, winter-spring, and spring. Predictions from models trained with Calanus had greater consistency across years than models trained without Calanus.

\section{Habitat suitability maps}

The results presented in Figs. $2 \& 3$ are quantitative summaries of 380 habitat suitability maps. We present a small subset of these maps in Fig. 4, which shows hindcasted habitat suitability (from the winterspring $_{\mathrm{C}}$ experiment) for all $8 \mathrm{~d}$ periods in 2002 during which whales were sighted. General patterns observed across all predicted habitat suitability maps are reported below.

A visual examination of right whale habitat suitability maps confirms what is reflected in the AUC scores. Years with high AUC tend to have more sightings in areas of high habitat suitability, and years with relatively low AUC tend to have fewer sightings in areas of high habitat suitability. The transition of whales from Cape Cod Bay to the Great South Channel, a well known phenomenon which has been documented in several studies (CETAP 1982, Winn et al. 1986, Kenney \& Wishner 1995, Kenney et al. 2001), was best reflected in maps from the winter-spring ${ }_{C}$ experiment. Maps from winter period experiments clearly showed that Cape Cod Bay is an area with high habitat suitability from 1 January to $21 \mathrm{March}$, but they did not capture the transition to the Great South Channel due to their short time span. Maps from the spring period experiments (22 March to 1 June) showed the shift in highly suitable habitat from Cape Cod Bay to the Great South Channel as habitat suitability in Cape Cod Bay declined, but that transition was less pronounced than that seen in maps from the winter-spring period experiments.

\section{Habitat preferences}

We used the relative influence of predictor variables (Table 2) in each model as a proxy for habitat preferences of right whales. Calanus was the most 

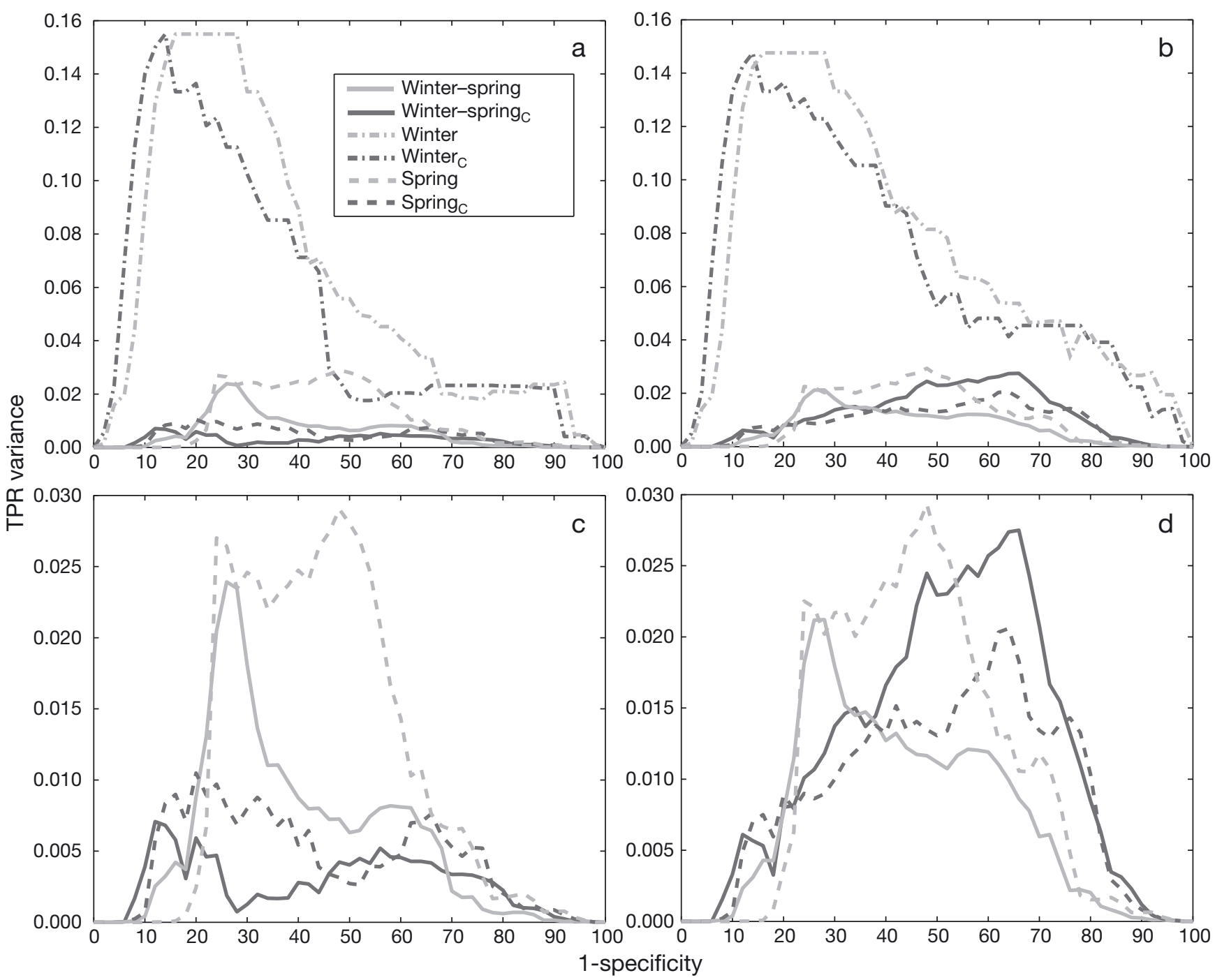

Fig. 3. Eubalaena glacialis. Variance in true positive rate (TPR) of right whale classification for each experiment, as a function of 1-specificity (pseudo-absence derived false positive rate), calculated from receiver operator characteristic (ROC) curves. Variance of each model $(\mathrm{a}, \mathrm{c})$ without and $(\mathrm{b}, \mathrm{d})$ with the result from 2006 . TPR variance $(\mathrm{a}, \mathrm{b})$ with and $(\mathrm{c}, \mathrm{d})$ without winter and

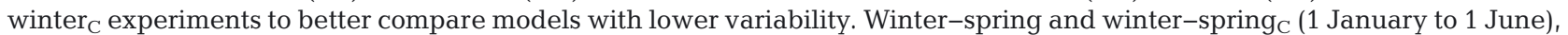
winter and winter $_{\mathrm{C}}(1 \mathrm{January}$ to $21 \mathrm{March})$, spring and spring $\mathrm{C}_{\mathrm{C}}(22 \mathrm{March}$ to $1 \mathrm{June}$ ). Subscript C indicates models in which Calanus was included as a predictor variable. Legend is the same for all subplots

influential predictor in the winter-spring ${ }_{C}$ experiment followed in importance by bathymetry, chlorophyll, and finally SST. The ranking was the same for the spring $\mathrm{C}_{\mathrm{C}}$ experiment in all years except 2004. The influence of Calanus was greater in the spring $_{C}$ than in the winter-spring ${ }_{C}$ experiment. When Calanus was not included as a predictor variable, in winterspring and spring experiments, the ranking of variable importance was bathymetry as the most influential, followed by chlorophyll and SST. The winter period experiments showed the opposite pattern: SST was the most influential predictor, followed by chlorophyll, bathymetry, and Calanus when it was included as a predictor variable. The winter ${ }_{C} 2006$ model was an exception to this ranking, with bathymetry $(22.9 \%)$ slightly more influential than chlorophyll $(22.6 \%)$.

\section{Predicted habitat suitability at whale occurrences during winter-spring}

There were clear differences in the value of environmental variables at the time and place of right whale occurrence. Modeled Calanus abundance was $<10$ ind. $\mathrm{m}^{-3}$ at $95 \%$ of winter right whale 

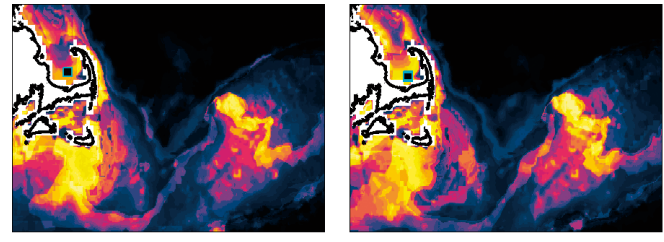

$2-9$ Feb

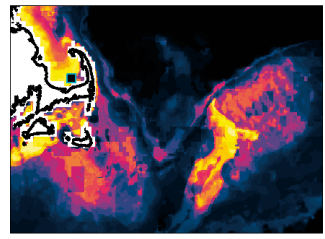

$14-21$ Mar

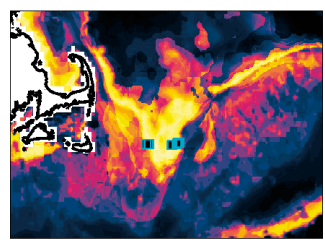

1 - 8 May

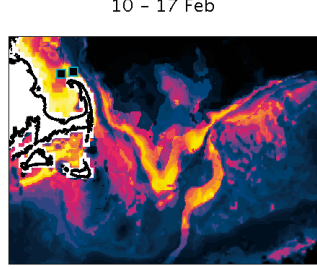

$30 \mathrm{Mar}-6 \mathrm{Apr}$

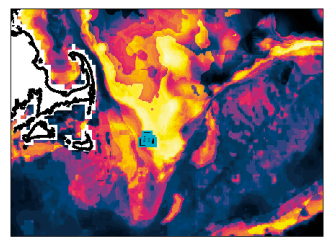

$9-16$ May

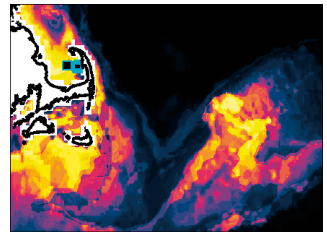

$18-25 \mathrm{Feb}$

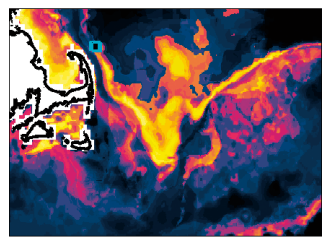

7 - 14 Apr

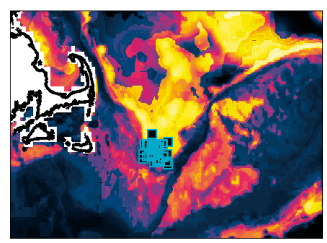

$17-24$ May

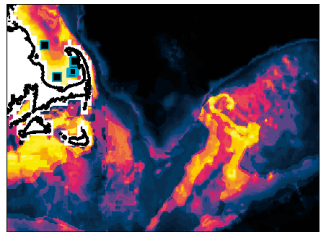

$26 \mathrm{Feb}-5 \mathrm{Mar}$

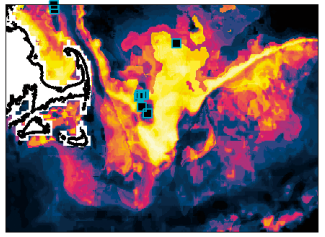

$15-22 \mathrm{Apr}$

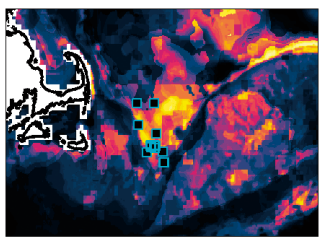

25 May - 1 Jun

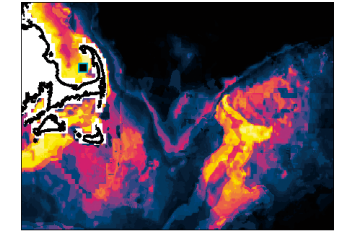

$6-13 \mathrm{Mar}$

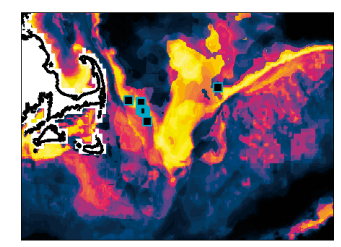

$23-30 \mathrm{Apr}$

Most suitable habitat $\square 1.0$

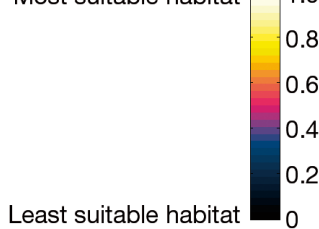

Fig. 4. Eubalaena glacialis. Hindcasts of right whale habitat suitability for all $8 \mathrm{~d}$ periods in 2002 during which right whales (squares) were sighted. White area at left is Cape Cod, Massachusetts. Per the color bar, black is low and white is high habitat suitability. All hindcasts are from the winter-spring ${ }_{C}$ experiment

Table 2. Percent variable contribution for all model test years 2002 to 2006, for all experiments: winter-spring and winterspring $_{C}$ experiments (1 January to 1 June), winter and winter ${ }_{C}$ and (1 January to 21 March), spring and spring $(22$ March to 1 June). Subscript C indicates models in which Calanus was included as a predictor variable. The greatest contribution to each model is shown in bold. SST: sea surface temperature, na: not applicable

\begin{tabular}{|c|c|c|c|c|c|c|c|}
\hline Test year & Predictor variable & Winter-spring & Winter-spring ${ }_{C}$ & Winter & Winter $_{\mathrm{C}}$ & Spring & Spring $_{C}$ \\
\hline \multirow[t]{4}{*}{2002} & Calanus & na & 35.3 & na & 10.8 & na & 45.1 \\
\hline & Bathymetry & 42.6 & 32.5 & 23.2 & 20.7 & 54.3 & 34.3 \\
\hline & Chlorophyll & 33.7 & 19.6 & 33.8 & 26.9 & 24.0 & 12.1 \\
\hline & SST & 23.7 & 12.6 & 43.0 & 41.7 & 21.7 & 8.4 \\
\hline \multirow[t]{4}{*}{2003} & Calanus & na & 37.6 & na & 17.6 & na & 44.4 \\
\hline & Bathymetry & 44.4 & 28.5 & 28.2 & 21.1 & 57.3 & 35.6 \\
\hline & Chlorophyll & 29.0 & 18.5 & 30.3 & 26.2 & 21.7 & 11.2 \\
\hline & SST & 26.6 & 15.4 & 41.6 & 35.1 & 21.0 & 8.8 \\
\hline \multirow[t]{4}{*}{2004} & Calanus & na & 36.9 & na & 18.7 & na & 35.7 \\
\hline & Bathymetry & 48.4 & 31.8 & 26.3 & 22.7 & 56.7 & 38.6 \\
\hline & Chlorophyll & 27.7 & 18.0 & 30.0 & 24.6 & 22.9 & 14.2 \\
\hline & $\mathrm{SST}^{1}$ & 23.9 & 13.4 & 43.7 & 34.0 & 20.4 & 11.4 \\
\hline \multirow{4}{*}{2005} & Calanus & na & 33.2 & na & 15.4 & na & 42.5 \\
\hline & Bathymetry & 45.0 & 31.6 & 26.7 & 20.6 & 60.6 & 39.0 \\
\hline & Chlorophyll & 35.0 & 19.2 & 27.9 & 24.3 & 21.4 & 11.4 \\
\hline & SST & 25.0 & 16.0 & 45.3 & 39.6 & 18.1 & 7.1 \\
\hline \multirow[t]{4}{*}{2006} & Calanus & na & 40.9 & na & 16.9 & na & 46.3 \\
\hline & Bathymetry & 47.7 & 31.0 & 26.5 & 22.9 & 61.4 & 34.9 \\
\hline & Chlorophyll & 27.8 & 15.8 & 31.4 & 22.6 & 20.7 & 11.6 \\
\hline & SST & 24.4 & 12.3 & 42.1 & 37.6 & 17.9 & 7.1 \\
\hline
\end{tabular}

occurrences (Fig. 5a). A portion of spring right whale occurrences were in areas of low Calanus; however, for a large portion of occurrences $(65 \%)$ modeled Calanus was $>10$ ind. $\mathrm{m}^{-3}$. There was a positive trend between predicted habitat suitability and modeled Calanus abundance during spring. Chlorophyll at right whale occurrences was generally higher in winter than in spring (Fig. 5b). Almost all of the whale occurrences during winter (75\%) were associated with chlorophyll values $>0.5\left(\log _{10}\right.$ 

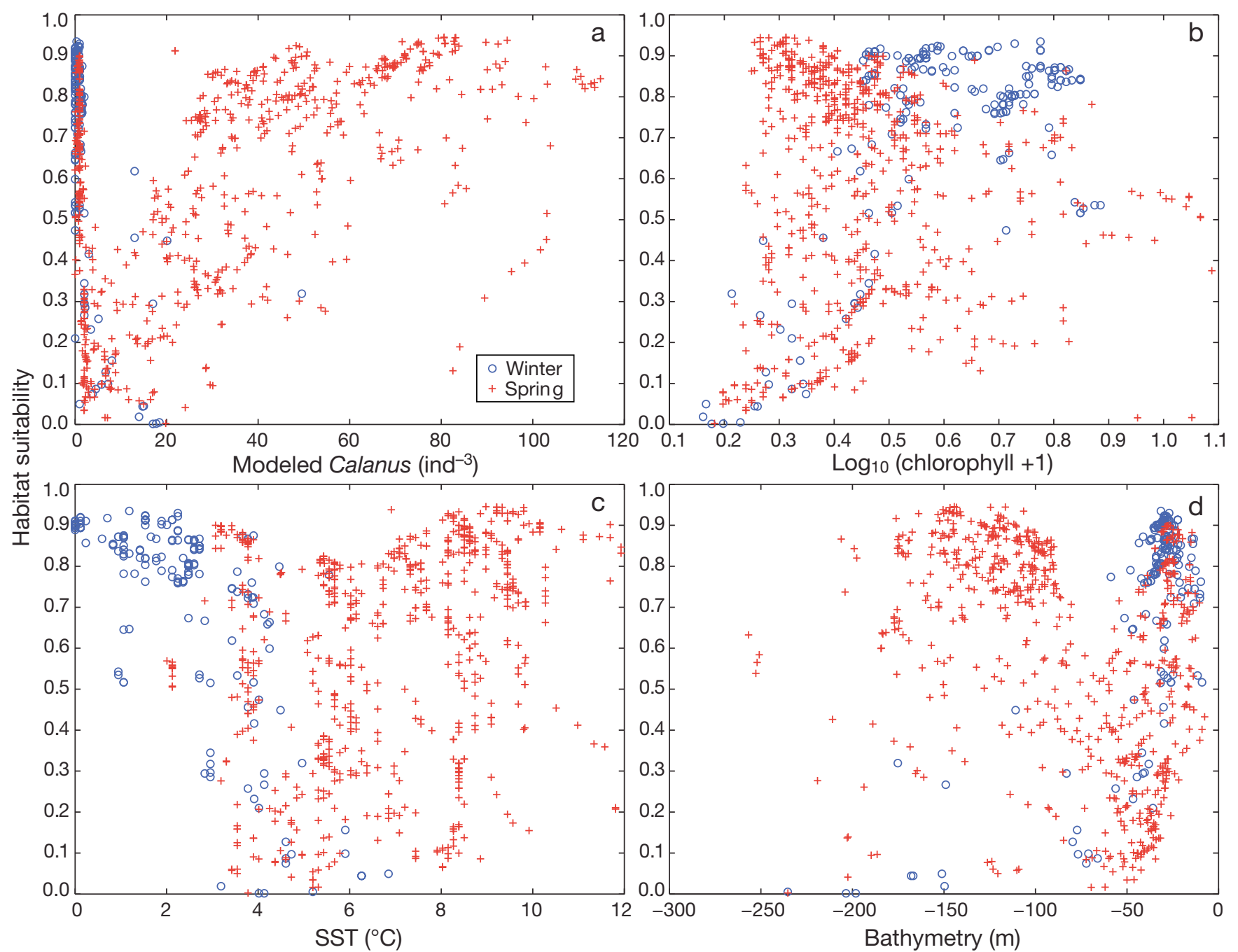

Fig. 5. Eubalaena glacialis. Habitat suitability values at each right whale presence location and time from 2002 to 2006 ( $\mathrm{N}=$ 989) versus: (a) modeled Calanus, (b) $\log _{10}$ (chlorophyll +1), (c) sea surface temperature (SST) and (d) bathymetry. Circles indicate right whale presence records from the winter period (1 January to $21 \mathrm{March}$ ). Crosses indicate right whale presences from the spring period (22 March to 1 June)

$[x+1])$, while $74 \%$ of spring right whale occurrences were associated with chlorophyll <0.5. During winter there was a cluster of whale sightings at SSTs less than $3^{\circ} \mathrm{C}$ and a steep decline thereafter (Fig. 5c). Eighty-eight percent of winter right whale sightings were associated with SST below $4^{\circ} \mathrm{C}$. Eighty-five percent of spring right whale sightings were associated with SST between 4 and $12^{\circ} \mathrm{C}$. There was no discernible trend in the temperature at whale occurrences during summer. There was a large cluster of winter right whale occurrences at a depth of less than $50 \mathrm{~m}$. Ninety-one percent of winter right whale occurrences were in water less than $63 \mathrm{~m}$ depth (the maximum depth of Cape Cod Bay), and $56 \%$ of spring right whale occurrences were in water greater than $63 \mathrm{~m}$ depth.

\section{DISCUSSION}

We found that weekly habitat suitability for North Atlantic right whales, a highly migratory marine mammal, can be hindcasted with reasonable accuracy using a species distribution model. In the vast majority of applications, species distribution models have used multi-year climatologically averaged predictor variables, such as those from the WorldClim database (Hijmans et al. 2005), yielding estimates of the absolute range or habitat suitability of a species. In such predictions, year-to-year variability is averaged out. While there has been some work on seasonal models (Suárez-Seoane et al. 2008), we believe our work to be the first application of a species distribution model on the weekly timescale. 


\section{$H_{1}$ : right whale habitat preferences are dynamic}

Differences in the influence of predictor variables on model results for winter/winter ${ }_{C}$ and spring/ spring $_{C}$ experiments (Table 2) suggest that the habitat preferences of right whales are not static. Results from models of the winter period suggest that the winter distribution of right whales is determined primarily by SST. The significance of ocean temperatures to right whales is not well understood. SST has been documented to be an important predictor of right whale distribution in certain areas. The distribution of SST at right whale occurrences in the southeast US right whale Critical Habitat is nonrandom (Keller et al. 2006), with right whales being found in waters cooler than $22^{\circ} \mathrm{C}$ (Good 2008). In the northern habitats such as the Bay of Fundy and Roseway Basin, where feeding is common, the influence of temperature on the distribution of right whales is less clear. Woodley \& Gaskin (1996) found significantly higher surface temperatures where right whales were present than where they were absent in the lower Bay of Fundy. Baumgartner et al. (2003b) found some indication that the SST gradient could explain interannual variability in right whale occurrence in Roseway Basin, adjacent to the Bay of Fundy. However, in that same area, Patrician \& Kenney (2010) did not find a relationship between SST and right whale abundance. Differing spatial and temporal scales of investigation confound comparison of these studies. The strong influence of temperature in our winter models may be a proxy for an environmental variable not considered in our study. The copepods Pseudocalanus spp. are important winter prey for right whales (Mayo et al. 2004), but temperature has not been found to impact the abundance of Pseudocalanus spp. (DeLorenzo Costa et al. 2006, Turner et al. 2011). It is also important to note that satellite-derived SST provides the temperature in only the first $\sim 1 \mathrm{~mm}$ of the ocean, and right whales spend a considerable amount of time at depth where temperatures are typically different.

Models for the winter-spring and spring periods were most heavily influenced by Calanus, with that variable being more important in models of spring than of the winter-spring period. An increased influence of Calanus as the year progresses agrees with what we have observed empirically: during winter in Cape Cod Bay, right whales feed on Pseudocalanus spp. and possibly Centropages spp. (Mayo \& Marx 1990), after which they transition to a diet of Calanus as that prey taxon becomes more abundant (Pendleton et al. 2009). Our results support the findings of several other studies that have found or inferred Calanus to be a major component of the right whale diet (Murison \& Gaskin 1989, Mayo \& Marx 1990, Wishner et al. 1995, Beardsley et al. 1996, Woodley \& Gaskin 1996, Baumgartner \& Mate 2003).

Right whales have been found in a wide range of depths. On the calving grounds in the southeast USA, right whales are commonly found in water 10 to $20 \mathrm{~m}$ deep, which is consistent with calving activity in that region (Garrison 2007). Our study found right whales in water with depths of 8 to $257 \mathrm{~m}$ in the Gulf of Maine. Aggregations of right whales regularly occur over the deep basins of the lower Bay of Fundy and Roseway Basin in waters 100 to $200 \mathrm{~m}$ deep. It is likely that bathymetric features give rise to physical and/or biological processes that are important to right whales.

Relative to other predictor variables, chlorophyll had a moderate influence on model results. Chlorophyll provides a reasonable proxy for phytoplankton abundance, which is directly related to Calanus egg production. The time lag between a phytoplankton bloom and increases in Calanus abundance mean that weekly chlorophyll data may not be a good indicator of Calanus, and thus right whale distributions. Hlista et al. (2009) found that a 2 yr lagged index of chlorophyll concentration (measured when right whales are expected in Cape Cod Bay, the Great South Channel, and the Bay of Fundy feeding habitats) was positively correlated with annual right whale calving numbers. Thus, on longer time scales, chlorophyll is an important variable to consider in right whale habitat models. Temporally lagged or longer-term averages of chlorophyll concentration may have provided a stronger predictor than the weekly averages used in our models.

We modeled the distribution of right whale habitat based upon only 4 predictor variables. It is widely thought that several other factors may influence right whale distributions, including thermal fronts and the bottom mixed layer (Baumgartner et al. 2003b), abundance of other prey species such as Pseudocalanus spp. and Centropages spp. (Mayo \& Marx 1990, Pendleton et al. 2009), and bottom type (Good 2008).

Our training data sets were constructed by associating each whale occurrence with average environmental conditions for the $8 \mathrm{~d}$ period in which the whale was observed. Right whales can travel a considerable distance in $1 \mathrm{wk}$ (Mate et al. 1997); therefore, the approximation of environmental conditions at the time of whale occurrence probably introduced some inaccuracy. A more precise model could be 
made by associating occurrences of non-transiting right whales with daily values of environmental conditions. Our results are based upon statistical relationships between known right whale presences and the value of predictor variables associated with those presence records. As with all results of correlative studies, our results are not necessarily indicative of physical or biological processes.

\section{$\mathrm{H}_{2}$ : prey data improve predictive accuracy}

Torres et al. (2008) found that predictive accuracy was not improved with the inclusion of prey data in a generalized additive model of bottlenose dolphin Tursiops truncatus habitat. In the present study, in 2 of the 3 time periods examined (winter-spring and spring), the inclusion of modeled prey abundance improved overall predictive accuracy (Fig. 2, Table 1), sensitivity to interannual environmental variability (Fig. 3), and the ability to discriminate good from bad habitat (i.e. greater range in habitat suitability values makes it easier to delineate differences). Because we are modeling right whale habitat suitability in areas where whales are known to feed much of the time (Mayo \& Marx 1990, Wishner et al. 1995), it makes sense that the availability of prey would be an important predictor of the distribution of whales.

Right whales feed on ultra-dense patches of copepods (Watkins \& Schevill 1976, Wishner et al. 1988, Mayo \& Marx 1990, Beardsley et al. 1996, Baumgartner et al. 2003a), often occurring at the scale of 1 to $10 \mathrm{~s}$ of meters. It is therefore interesting that our estimates of copepod abundance at $1 \mathrm{~km}$ resolution served as an important predictor of the distribution of potential right whale habitat, given that the modeled copepod fields do not contain patches. This, along with the studies of Pendleton et al. (2009) and Pershing et al. (2009b), reinforce the view that high regional-scale mean abundance of copepods increases the likelihood of formation of ultra-dense patches of copepods. Under this view, adding SST, chlorophyll, and bathymetry to the habitat model may indicate the physical conditions that encourage patch formation.

\section{Interannual variability}

Interannual variability was well captured in results

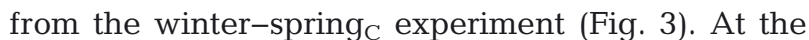
other end of the spectrum were the models of the winter period, which performed well in some years and poorly in other years. The high variability in winter models (Fig. 3a,b) may be an indication that we are missing an important environmental variable, such as Pseudocalanus spp., a winter taxon which is thought to be an important resource for right whales during winter (Mayo \& Marx 1990, Pendleton et al. 2009).

Another important consideration is the influence of sample size on AUC. Hernandez et al. (2006) and Wisz et al. (2008) found that models trained with fewer presences have a lower AUC. Our models of the winter season were trained on considerably fewer presence locations than models for winterspring or spring periods. However, the lowest number of presences used in any of our models ( $\mathrm{N}=86$ in winter 2004 and winter $_{C}$ 2004) was well above the number of presence locations that produced artificially low AUC values in Hernandez et al. (2006) and Wisz et al. (2008). There were relatively few presence locations available for testing winter $2002(\mathrm{~N}=$ 18) and winter $2004(\mathrm{~N}=7)$ (Table 1). Using a small number of test points to construct a ROC curve will result in a curve with fewer nodes or points to connect. This could result in an over- or underestimate of the AUC that would have been calculated with a large number of test points.

Models fit with Calanus from the winter-spring and spring periods for 2006 did not perform well (Table 1). This, along with the fact that models fit with data from winter and tested in 2006 (with and without Calanus) were not far from average leads us to believe that the modeled distribution of Calanus in the spring was responsible for the poor predictions. Alternatively, right whales may have had a strong response to an environmental covariate that we did not model, such as Pseudocalanus spp., or right whales may have been drawn to a more suitable habitat outside of our model domain (and outside of the typical range of right whales in winter and spring). We analyzed the spatial and temporal patterns of sighting data in 2006 versus 2002 to 2005 and found that the distribution of whales in 2006 was not unusual in comparison to 2002 to 2005. An examination of environmental variables revealed that modeled Calanus abundances were anomalously high between late March and late May of 2006. This means that the models trained with data from 2002 to 2005 were informed by relatively low springtime abundances of modeled Calanus and were tested in a year with relatively high springtime abundances of modeled Calanus. This difference in training and testing levels of Calanus probably contributed to below average performance of winter-spring ${ }_{C}$ and spring $_{\mathrm{C}}$ models for 2006. 


\section{CONCLUSIONS}

We have found that right whale habitat suitability can be estimated on a weekly timescale with only 4 predictor variables. Models that incorporated data from both winter and spring seasons were more accurate and provided more consistent performance than winter-only or spring-only models. Our results confirmed empirical observations that right whale habitat preferences change on a seasonal timescale. The inclusion of prey as a predictor variable improved predictive accuracy of models. The framework presented here is an important step toward the goal of having a near real-time habitat modeling system that could be used to answer ecological questions and assess risk to endangered species by proposed management actions. Our approach could also be extended to other populations of highly mobile animals, both on land and in the ocean.

Acknowledgements. We thank the North Atlantic Right Whale Consortium for providing right whale occurrence records, and NOAA-NODC for providing satellite data. This work was supported by NASA's Applied Sciences program and NSF's Information Technology Research Program. We thank numerous marine mammal observers who helped collect the right whale occurrence data used in this study. We are grateful to 4 anonymous reviewers for their constructive criticism and helpful comments.

\section{LITERATURE CITED}

Baumgartner MF, Mate BR (2003) Summertime foraging ecology of North Atlantic right whales. Mar Ecol Prog Ser 264:123-135

Baumgartner MF, Cole TVN, Campbell RG, Teegarden GJ, Durbin EG (2003a) Associations between North Atlantic right whales and their prey, Calanus finmarchicus, over diel and tidal time scales. Mar Ecol Prog Ser 264:155-166

Baumgartner MF, Cole TVN, Clapham PJ, Mate BR (2003b) North Atlantic right whale habitat in the lower Bay of Fundy and on the SW Scotian Shelf during 1999-2001. Mar Ecol Prog Ser 264:137-154

Beardsley RC, Epstein AW, Chen CS, Wishner KF, Macaulay MC, Kenney RD (1996) Spatial variability in zooplankton abundance near feeding right whales in the Great South Channel. Deep-Sea Res II 43:1601-1625

Brown MW, Kraus SD, Slay CK, Garrison LP (2007) Surveying for discovery, science, and management. In: Kraus SD, Rolland RM (eds) The urban whale: North Atlantic right whales at the crossroads. Harvard University Press, Cambridge, MA, p 105-137

Brown MW, Fenton D, Smedbol K, Merriman C, RobichaudLeBlanc K, Conway J (2009) Recovery strategy for the North Atlantic right whale (Eubalaena glacialis) in Atlantic Canadian waters. Species at Risk Act Recovery Strategy Series. Fisheries and Oceans Canada, Ottawa

Campbell RG, Wagner MM, Teegarden GJ, Boudreau CA, Durbin EG (2001) Growth and development rates of the copepod Calanus finmarchicus reared in the laboratory. Mar Ecol Prog Ser 221:161-183

CETAP (Cetacean and Turtle Assessment Program) (1982) A characterization of marine mammals and turtles in the mid-and North Atlantic areas of the U.S. outer continental shelf. Final report, contract no. AA551-CT8-48, Bureau of Land Management, Washington, DC

Cole TVN, Gerrior P, Merrick RL (2007) Methodologies and preliminary results of the NOAA National Marine Fisheries Service aerial survey program for right whales (Eubalaena glacialis) in the northeast U.S., 1998-2006. Northeast Fish Sci Cent Ref Doc 07-02. National Marine Fisheries Service, Woods Hole, MA

> DeLorenzo Costa A, Durbin EG, Mayo CA, Lyman EG (2006) Environmental factors affecting zooplankton in Cape Cod Bay: implications for right whale dynamics. Mar Ecol Prog Ser 323:281-298

> Durbin EG, Campbell RG, Gilman SL, Durbin AG (1995) Diel feeding behavior and ingestion rate in the copepod Calanus finmarchicus in the southern Gulf of Maine during late spring. Cont Shelf Res 15:539-570

> Durbin EG, Campbell RG, Casas MC, Ohman MD, Niehoff B, Runge J, Wagner M (2003) Interannual variation in phytoplankton blooms and zooplankton productivity and abundance in the Gulf of Maine during winter. Mar Ecol Prog Ser 254:81-100

Efron B, Tibshirani RJ (1994) An introduction to the bootstrap. Chapman \& Hall/CRC, New York, NY

Elith J, Phillips SJ, Hastie T, Dudík M, Chee YE, Yates CJ (2011) A statistical explanation of MaxEnt for ecologists. Divers Distrib 17:43-57

Fawcett T (2006) An introduction to ROC analysis. Pattern Recogn Lett 27:861-874

NOAA (National Oceanic and Atmospheric Administration) (1994) Designated critical habitat; northern right whale. Fed Reg 59:28805

NOAA (National Oceanic and Atmospheric Administration) (2002) Taking of marine mammals incidental to commercial fishing operations; Atlantic large whale take reduction plan regulations. Fed Reg 67:1142

NOAA (National Oceanic and Atmospheric Administration) (2008) Endangered fish and wildlife; final rule to implement speed restrictions to reduce the threat of ship collisions with North Atlantic right whales. Fed Reg 73:60173

Ferrier S, Watson G, Pearce J, Drielsma M (2002) Extended statistical approaches to modelling spatial pattern in biodiversity in northeast New South Wales. I. Species-level modelling. Biodivers Conserv 11:2275-2307

Garrison LP (2007) The big picture: modeling right whales in space and time. In: Kraus SD, Rolland RM (eds) The urban whale: North Atlantic right whales at the crossroads. Harvard University Press, Cambridge, MA, p 460-487

Good C (2008) Spatial ecology of the North Atlantic right whale (Eubalaena glacialis). PhD dissertation, Duke University, Durham, NC

Goodyear JD (1996) Significance of feeding habitats of North Atlantic right whales based on studies of diel behavior, diving, food ingestion rates, and prey. PhD dissertation, The University of Guelph

> Hanley JA, McNeil BJ (1982) The meaning and use of the area under a receiver operating characteristic (ROC) curve. Radiology 143:29-36

Hernandez PA, Graham CH, Master LL, Albert DL (2006) The effect of sample size and species characteristics on 
performance of different species distribution modeling methods. Ecography 29:733-785

- Hijmans RJ, Cameron SE, Parra JL, Jones PG, Jarvis A (2005) Very high resolution interpolated climate surfaces for global land areas. Int J Climatol 25:1965-1978

Hirzel AH, Hausser J, Chessel D, Perrin N (2002) Ecologicalniche factor analysis: How to compute habitat-suitability maps without absence data? Ecology 83:2027-2036

Hlista BL, Sosik HM, Traykovski LVM, Kenney RD, Moore MJ (2009) Seasonal and interannual correlations between right-whale distribution and calving success and chlorophyll concentrations in the Gulf of Maine, USA. Mar Ecol Prog Ser 394:289-302

> Jossi JW, Goulet JR (1993) Zooplankton trends: United States northeast shelf ecosystem and adjacent regions differ from Northeast Atlantic and North Sea. ICES J Mar Sci 50:303-313

Keller CA, Ward-Geiger LI, Brooks WB, Slay CK, Taylor CR, Zoodma BJ (2006) North Atlantic right whale distribution in relation to sea-surface temperature in the southeastern United States calving grounds. Mar Mamm Sci 22: 426-445

Kenney RD (2001) Anomalous 1992 spring and summer right whale (Eubalaena glacialis) distributions in the Gulf of Maine. J Cetacean Res Manag 2(Spec Issue):209-223

Kenney RD, Wishner KF (1995) The South Channel Ocean Productivity Experiment. Cont Shelf Res 15:373-384

Kenney RD, Mayo CA, Winn HE (2001) Migration and foraging strategies at varying spatial scales in western North Atlantic right whales: a review of hypotheses. J Cetacean Res Manag 2(Spec Issue):251-260

Knowlton AR, Kraus SD (2001) Mortality and serious injury of northern right whales (Eubalaena glacialis) in the western North Atlantic Ocean. J Cetacean Res Manag 2(Spec Issue):193-208

Kraus SD, Brown MW, Caswell H, Clark CW and others (2005) North Atlantic right whales in crisis. Science 309: 561-562

Kraus SD, Pace RM III, Frasier TR (2007) High investment, low return: the strange case of reproduction in Eubalaena glacialis. In: Kraus SD, Rolland RM (eds) The urban whale: North Atlantic right whales at the crossroads. Harvard University Press, Cambridge, MA, p 172-199

Mate BR, Nieukirk SL, Kraus SD (1997) Satellite-monitored movements of the northern right whale. J Wildl Manag 61:1393-1405

Mayo CA, Marx MK (1990) Surface foraging behaviour of the North Atlantic right whale, Eubalaena glacialis, and associated zooplankton characteristics. Can J Zool 68: 2214-2220

Mayo CA, Nichols OC, Bessinger MK, Brown MW, Marx MK, Browning CL (2004) Surveillance, monitoring and management of North Atlantic right whales in Cape Cod Bay and adjacent waters - 2004. Final report submitted to the Commonwealth of Massachusetts, Division of Marine Fisheries, Center for Coastal Studies, Provincetown, MA

> Murison LD, Gaskin DE (1989) The distribution of right whales and zooplankton in the Bay of Fundy, Canada. Can J Zool 67:1411-1420

> Myers RA, Boudreau SA, Kenney RD, Moore MJ, Rosenberg AA, Sherrill-Mix SA, Worm B (2007) Saving endangered whales at no cost. Curr Biol 17:R10-R11

Naimie CE (1996) Georges Bank residual circulation during weak and strong stratification periods: prognostic numerical model results. J Geophys Res 101:6469-6486 doi: 10.1029/95JC03698

NARWC (North Atlantic Right Whale Consortium) (2011a) North Atlantic Right Whale Consortium sightings database. New England Aquarium, Boston, MA

Patrician MR, Kenney RD (2010) Using the continuous plankton recorder to investigate the absence of North Atlantic right whales (Eubalaena glacialis) from the Roseway Basin foraging ground. J Plankton Res 32: 1685-1695

Pendleton DE, Pershing AJ, Brown MW, Mayo CA, Kenney RD, Record NR, Cole TVN (2009) Regional-scale mean copepod concentration indicates relative abundance of North Atlantic right whales. Mar Ecol Prog Ser 378: 211-225

Pershing AJ, Record NR, Monger BC, Pendleton DE, Woodard LA (2009a) Model-based estimates of Calanus finmarchicus abundance in the Gulf of Maine. Mar Ecol Prog Ser 378:227-243

> Pershing AJ, Record NR, Monger BC, Mayo CA and others (2009b) Model-based estimates of right whale habitat use in the Gulf of Maine. Mar Ecol Prog Ser 378:245-257

> Phillips SJ, Dudík M (2008) Modeling of species distributions with Maxent: new extensions and a comprehensive evaluation. Ecography 31:161-175

Phillips SJ, Dudík M, Schapire RE (2004) A maximum entropy approach to species distribution modeling. In: Proc 21st Int Conf Machine Learning. ACM Press, New York, NY, p 655-662

Phillips SJ, Anderson RP, Schapire RE (2006) Maximum entropy modeling of species geographic distributions. Ecol Model 190:231-259

> Phillips SJ, Dudík M, Elith J, Graham CH, Lehmann A, Leathwick J, Ferrier S (2009) Sample selection bias and presence-only distribution models: implications for background and pseudo-absence data. Ecol Appl 19:181-197

Runge JA, Plourde S (1996) Fecundity characteristics of Calanus finmarchicus in coastal waters of eastern Canada. Ophelia 44:171-187

Smith WHF, Sandwell DT (1997) Global sea floor topography from satellite altimetry and ship depth soundings. Science 277:1956-1962

- Suárez-Seoane S, García de la Morena EL, Prieto MBM, Osborne PE, de Juana E (2008) Maximum entropy nichebased modelling of seasonal changes in little bustard (Tetrax tetrax) distribution. Ecol Model 219:17-29

Swets JA (1988) Measuring the accuracy of diagnostic systems. Science 240:1285-1293

Torres LG, Read AJ, Halpin P (2008) Fine-scale habitat modeling of a top marine predator: Do prey data improve predictive capacity? Ecol Appl 18:1702-1717

Turner JT, Borkman DG, Libby PS (2011) Zooplankton trends in Massachusetts Bay, USA: 1998-2008. J Plankton Res 33:1066-1080

- Ward-Geiger LI, Silber GK, Baumstark RD, Pulfer TL (2005) Characterization of ship traffic in right whale critical habitat. Coast Manag 33:263-278

Watkins WA, Schevill WE (1976) Right whale feeding and baleen rattle. J Mammal 57:58-66

Winn HE, Price CA, Sorensen PW (1986) The distributional biology of the right whale (Eubalaena glacialis) in the western North Atlantic. Rep Int Whal Comm Spec Issue 10:129-138

Wishner KF, Durbin EG, Durbin A, Macaulay MC, Winn HE, Kenney RD (1988) Copepod patches and right whales in 
the Great South Channel off New England. Bull Mar Sci 43:825-844

Wishner KF, Schoenherr JR, Beardsley R, Chen CS (1995) Abundance, distribution and population structure of the copepod Calanus finmarchicus in a springtime right whale feeding area in the southwestern Gulf of Maine. Cont Shelf Res 15:475-507

> Wisz MS, Hijmans RJ, Li J, Peterson AT, Graham CH, Guisan A (2008) Effects of sample size on the perform-

Editorial responsibility: Mark Baumgartner, Woods Hole, Massachusetts, USA ance of species distribution models. Divers Distrib 14: 763-773

Woodley TH, Gaskin DE (1996) Environmental characteristics of North Atlantic right and fin whale habitat in the lower Bay of Fundy, Canada. Can J Zool 74:75-84

Zhang C, Hu C, Shanga S, Müller-Karger FE and others (2006) Bridging between SeaWiFS and MODIS for continuity of chlorophyll-a concentration assessments off southeastern china. Remote Sens Environ 102:250-263

Submitted: January 16, 2011; Accepted: April 14, 2012 Proofs received from author(s): July 30, 2012 